\title{
The health-related utility and health-related quality of life of hospital-treated subjects with type 1 or type 2 diabetes with particular reference to differing severity of peripheral neuropathy
}

\author{
C. J. Currie • C. D. Poole • A. Woehl • C. Ll. Morgan • \\ S. Cawley • M. D. Rousculp • M. T. Covington • \\ J. R. Peters
}

Received: 19 January 2006 / Accepted: 20 June 2006 / Published online: 30 August 2006

(C) Springer-Verlag 2006

\begin{abstract}
Aims/hypothesis We characterised symptom severity of diabetic peripheral neuropathy (DPN) in people with diabetes, and correlated this with health-related utility and health-related quality of life.

Materials and methods The study was undertaken in Cardiff and the Vale of Glamorgan, Wales. A postal survey was mailed to a random sample of subjects identified as having diabetes. Data were collected on the symptoms of neuropathy using the Neuropathic Total Symptom Score (self-administered) (NTSS-6-6A) and on quality of life using the Quality of Life in Diabetes Neuropathy Instrument (QoL-DN), EueroQoL five dimensions (EQ5D) and
\end{abstract}

C.J. Currie · C. Ll. Morgan

Department of Medicine, School of Medicine, Cardiff University, Cardiff, UK

C. D. Poole $\cdot$ A. Woehl

Cardiff Research Consortium, Health Park,

Cardiff, UK

S. Cawley

Department of Podiatry, University Hospital of Wales,

Cardiff, UK

M. D. Rousculp $\cdot$ M. T. Covington

Global Health Outcomes Research, Eli Lilly and Company,

Indianapolis, IN, USA

\section{J. R. Peters}

Department of Medicine, University Hospital of Wales,

Cardiff, UK

C. J. Currie $(\square)$

Department of Medicine,

University Hospital of Wales, Heath Park,

Cardiff CF14 4XW, UK

e-mail: currie@cardiff.ac.uk
Short Form 36 (SF36). Other information, such as demographics and self-reported drug use, was also collected. The anonymised data were linked to routine inpatient and outpatient healthcare data.

Results Responses were received from 1,298 patients. For patients with a clinically confirmed diagnosis of DPN, the mean NTSS-6-SA score was 6.16 vs 3.19 in patients without DPN $(p<0.001)$. Four categories of severity were defined, ranging from none to severe. All quality of life measures showed a deterioration between these groups: the $\mathrm{EQ} \mathrm{D}_{\text {index }}$ fell from an average of 0.81 in those without symptoms to 0.25 in those with severe symptoms, the SF36 general health profile fell from 59.9 to $25.5(p<0.001)$ and the QoL-DN increased from 25.8 to $48.1 \quad(p<0.001)$. Multivariate models also demonstrated that this relationship remained after controlling for other factors.

Conclusions/interpretation This study demonstrated that severity of DPN symptoms was predictive of poor healthrelated utility and decreased quality of life. Furthermore, it provides detailed utility data for economic evaluation of treatment of typical diabetes-related morbidity states. Reducing DPN morbidity should be a priority.

Keywords Diabetes - EQ5D - Health-related utility · Neuropathy $\cdot$ NTSS $\cdot$ Quality of life $\cdot$ SF36

$\begin{array}{ll}\text { Abbreviations } \\ \text { DPN } & \text { diabetic peripheral neuropathy } \\ \text { EQ5D } & \text { EueroQoL five dimensions } \\ \text { GLM } & \text { general linear model } \\ \text { HODaR } & \text { Health Outcomes Data Repository } \\ \text { HRQoL } & \text { health-related quality of life } \\ \text { ICD-10 } & \begin{array}{l}\text { International Classification of Diseases, 10th } \\ \text { revision }\end{array}\end{array}$


NTSS-6 Neuropathic Total Symptom Score (six domains)

NTSS-6- Neuropathic Total Symptom Score (self-

SA administered)

PVD peripheral vascular disease

QoL-DN Quality of Life in Diabetes Neuropathy instrument

SF36 Short Form 36

$\mathrm{SF} 36_{\mathrm{GHP}} \quad \mathrm{SF} 36$ global health profile

\section{Introduction}

Diabetic peripheral neuropathy (DPN) is among the most common long-term microvascular complications of diabetes and leads not only to considerable patient morbidity but also increased mortality. A prevalence rate of $50 \%$ after 15 to 20 years of disease duration has been reported [1]. The most common form of DPN is detected in about $30 \%$ of type 1 and type 2 patients $[2,3]$. In the UK, half a million people will be diagnosed with DPN by 2010 [4].

Complications of DPN such as lower extremity ulcers are experienced by $15 \%$ of patients [5]. Studies evaluating health-related quality of life (HRQoL) have shown that patients with foot ulcers have decreased physical, emotional and social function [6]. Several small studies have focused on the impact of the pain [7, 8]. Analysis of data from the Epidemiology of Diabetes Complications Study showed that in type 1 diabetes DPN was significantly associated with reduced physical function, increased bodily pain and decreased vitality [9]. DPN has been found to be a determinant of mental health [10]. Clinical data do not always correlate well with HRQoL in DPN [11-13].

Until recently investigators have not sought to accurately classify the severity of DPN. A new instrument, the Neuropathy Total Symptom Score (six domains) (NTSS-6) has been developed for use in both a physician-administered format and a self-administered format (NTSS-6-SA). This instrument may allow for earlier diagnosis of DPN and more precise research into its progression and its impact. The NTSS-6-SA has been shown to be a reliable and valid [14] instrument for assessing the symptoms of DPN, correlating closely with health-related utility [15] and health-related quality of life [16]. The NTSS-6-SA has been applied in the evaluation of both pharmacological [17] and non-pharmacological interventions [18].

The aim of this study was to accurately characterise DPN symptom severity in people with diabetes, along with its association with health utility and HRQoL. It was hypothesised that both heath-related utility and HRQoL would decrease with increasing severity of DPN.

\section{Subjects, materials and methods}

Survey

This study was undertaken in Cardiff and the Vale of Glamorgan, Wales, in the third largest Hospital Trust in the UK. A postal survey was mailed to patients, identified at random from hospital records, who were known to have been diagnosed with either type 1 or type 2 diabetes using the same methods as the Health Outcomes Data Repository (HODaR) [19]. HODaR comprises a comprehensive survey of demographic and lifestyle data, health utility (EueroQoL five dimensions [EQ5D $\left.\mathrm{D}_{\text {index }}\right]$ ), HRQoL (Short Form 36 [SF36]), resource use, some drug use and other characteristics. Symptoms of neuropathy were assessed using the NTSS-6-SA and the Quality of Life in Diabetes Neuropathy (QoL-DN) instruments [20].

Patient identification

Eligibility to receive a survey questionnaire was determined by the following criteria. Patients were chosen if an outpatient or inpatient consultant episode had recorded an International Classification of Diseases, 10th revision (ICD10) diagnosis E10* or E11* (type 1 or type 2 diabetes, respectively). Patients were excluded from the study if they: (1) had completed another HODaR survey in the previous 6 months; (2) had a diagnosis of gestational diabetes (ICD$10, \mathrm{O} 24.4)$; or (3) were less than 18 years of age.

Diabetes and neuropathy diagnosis

Type of diabetes was assigned using the following rules: if the diagnosis was recorded as ICD-10 code then it was included (note: a diagnosis of type 1 diabetes superseded a record of type 2 diabetes where any conflict existed); and if there was no recorded diagnosis and a patient was $\leq 30$ years of age a diagnosis of type 1 diabetes was attributed.

Podiatry clinical data were available for a small subgroup of patients ( $n=161)$ enabling a clinical diagnosis of neuropathy to be made if there was a record of vibration loss using a neurothesiometer $\geq 25 \mathrm{~V}$, or recorded vibration loss using a Rydel Seiffer graduated tuning fork $\leq 4$, or recorded lightpressure sensation loss using a 10-g monofilament $(<7$ positive sites out of ten).

\section{Survey instruments}

In addition to the routine HODaR survey containing the EQ5D and the SF36, two disease-specific instruments were also included plus a small number of other important questions such as diabetes duration. The survey therefore included four outcome instruments: (1) the EQ5D to 
estimate health-related utility [21]; the SF36 as a generic measure of quality of life [22]; (3) the NTSS-6-SA DPN symptom score [14]; and (4) the QoL-DN [20].

The NTSS-6-SA measures the frequency and intensity of six DPN symptoms: numbness, sensitivity (allodynia), prickling, and three types of pain: aching, burning and sharp pain (termed 'lancinating pain' on the original NTSS6 survey). The NTSS-6-SA measures not only intensity but also frequency of the respective symptom.

Health utility was estimated using the EQ5D calculated using the original tariff [23]. EQ5D is based upon five domains: mobility, self-care, usual activities, pain and discomfort, and anxiety and depression. Each domain was scored into three categories: no problems, some problems and serious problems. An overall score was then calculated by subtracting a weighted value for each category from 1 . An individual who had no problems in any domain would thus score 1, that is, a state of perfect health. SF36 domain scores were generated using the Rand system [24]. A description of the taxonomy of the SF36 questions and domains is available online [25]. Based on the distribution of the final data, four NTSS-6-SA categories were derived: None, where the total score was 0 ; and thirtiles of the remainder making Mild (NTSS-6-SA $>0$ and $\leq 3.33$ ), Moderate $(>3.33$ and $\leq 7.64)$ and Severe $(>7.64)$.

\section{Complications}

Existing diabetic vascular complications were assigned on the basis of previous inpatient admission with a relevant diagnosis recorded as either a primary or secondary cause of admission. These were coded using the ICD-10 classification as follows: acute myocardial infarction (I21I22), stroke (I600-9), peripheral vascular disease (PVD) (I702, I730-I739, I792), end-stage renal disease (I120, N170-N199), retinopathy (H350-H369) and severe vision loss (H540-H546). Amputation was assigned on the basis of previous admission with one of four operation fields coded for lower limb amputation using the OPCS-4 classification (X09-X12).

\section{Medication use}

Current drug use was self-reported by the respondents detailing drug type, daily frequency and dosage. Data entry was supervised and quality assured by a clinically trained pharmacist (C. D. Poole).

British National Formulary (BNF) categories were assigned from the NHS Read Code mapping tables. As some drug products have more than one therapeutic moiety and/or more than one clinical indication, where a drug mapped to more than one BNF category the appropriateness of the mapping was examined by the trained pharmacist.
Statistical analysis

Multivariate generalised linear modelling (GLM) was then used in two stages to explore the independence of the univariate associations. Initially all variables were tested simultaneously; the models were then refined to exclude all variables whose $\beta$ values had not reached threshold significance, for this study set at the conventional level of $p=0.05$. Where tests of statistical significance have been used, these are listed explicitly.

\section{Results}

Survey response

Of the 4,075 questionnaires mailed, 1,298 were returned with no reminders (following the HODaR protocol); a crude response rate of $32 \%$. The demographic characteristics of responders and non-responders were examined to identify potential non-response bias. Non-responders

Table 1 Patient characteristics according to diabetes type

\begin{tabular}{llll}
\hline Parameter & Type 1 & Type 2 & $p$ \\
\hline Number of respondents (\%) & $236(21)$ & $889(89)$ & \\
Demographics & & & \\
Sex (\% male) & 51.7 & 59.2 & $0.019^{\mathrm{a}}$ \\
Age, years (SD) & $54.8(17.8)$ & $68.9(9.6)$ & $<0.001^{\mathrm{b}}$ \\
Complication risk factors & & & \\
Diabetes duration (years) & 20.1 & 10.9 & $<0.001^{\mathrm{c}}$ \\
Smokers (\%) & 11.9 & 11.1 & $0.809^{\mathrm{a}}$ \\
Years smoked & 11.8 & 16.7 & $0.001^{\mathrm{c}}$ \\
BMI, mean (SD) & 28.70 & 29.0 & $0.426^{\mathrm{b}}$ \\
& $(5.39)$ & $(5.42)$ & \\
HbA 1 , \%, mean (SD) & $8.34(1.59)$ & $7.6(1.44)$ & $<0.001^{\mathrm{b}}$ \\
Complication rates (\%) & & & \\
Acute myocardial infarction & 5.5 & 5.4 & $0.948^{\mathrm{a}}$ \\
Stroke & 5.1 & 4.2 & $0.537^{\mathrm{a}}$ \\
Amputation & 2.1 & 0.7 & $0.045^{\mathrm{a}}$ \\
PVD, no amputation & 5.1 & 3.6 & $0.295^{\mathrm{a}}$ \\
PVD, with amputation & 1.3 & 0.7 & $0.407^{\mathrm{d}}$ \\
Suffer/ed leg ulcer & 13.6 & 9.8 & $0.107^{\mathrm{a}}$ \\
End-stage renal disease & 11.4 & 6.2 & $0.006^{\mathrm{a}}$ \\
Retinopathy & 22.9 & 14.6 & $0.002^{\mathrm{a}}$ \\
Severe loss of vision & 1.3 & 0.1 & $0.031^{\mathrm{d}}$ \\
Health utility/quality of life & & & \\
EQ5D & & 0.59 & $0.629^{\mathrm{c}}$ \\
SF36 & & & \\
& & & \\
GHP (SD) & $39.6(25.9)$ & 45.4 & $0.003^{\mathrm{b}}$ \\
NTSS-6-SA & 4.70 & 3.92 & $0.298^{\mathrm{c}}$ \\
QoL-DN & 35.51 & 34.63 & $0.863^{\mathrm{c}}$ \\
\hline
\end{tabular}

${ }^{\mathrm{a} C h i}$-square test

${ }^{\text {b}}$ Student's $t$-test

${ }^{\mathrm{c}}$ Mann-Whitney $U$-test

${ }^{\mathrm{d}}$ Fisher's exact test 
tended to be slightly younger and a slightly higher proportion were female; differences that were statistically significant.

Respondents characteristics

Diabetes type was clearly classified in $1,125(87 \%)$ cases, $21 \%$ of which were of type 1 diabetes. Overall, $56 \%$ of respondents were male and the mean age was 64 years. Breakdown by sex was more even among people with type 1 diabetes, who also had a lower mean age (Table 1). The duration of diabetes in type 1 patients was double that of the type 2 cases (20.1 vs 10.9 years; $p<0.001)$ and their mean $\mathrm{HbA}_{1 \mathrm{c}}$ was significantly higher (8.34 vs $7.67 \% ; p<0.001)$. Neuropathyrelated complications tended to occur more often in type 1 patients, although interestingly, neither the NTSS-6-SA score nor the QoL-DN score differed by type of diabetes (4.70 vs $3.92 ; p=0.298$ and 35.51 vs $34.63 ; p=0.863$, respectively).
Health utility and quality of life

In those patients with a clinically confirmed diagnosis of DPN the mean NTSS-6-SA score was 6.16 vs 3.19 $(p<0.001)$ in those who had no diagnosis.

Patient characteristics were also examined across the four derived NTSS-6-SA categories (Table 2). Mean BMI increased with symptom severity from 28.0 to $30.9 \mathrm{~kg} / \mathrm{m}^{2}$, $p<0.001)$. The likelihood of having an existing or previous leg ulcer increased with increasing symptom severity (range: $5.1-19.6 \% ; p<0.001$ ), as did the rate of PVD (range: $0.6-8.4 \% ; p<0.001$ ).

Mean utility and quality of life scores changed dramatically across the NTSS-6-SA score category. Utility fell from an average of 0.81 in Group-None to just 0.25 in Group-Severe $(p<0.001)$. Both generic and disease-specific quality of life as measured by the SF36 $6_{\mathrm{GHP}}$ (3F36 global health profile) and QoL-DN, respectively, also showed marked changes consistent with increasing symptom severity. Those with no symptoms had a mean SF36 $6_{\mathrm{GHP}}$ score of 59.9 , whilst those with the severest symptoms had a mean $\mathrm{SF} 36_{\mathrm{GHP}}$ score of just $25.5(p<0.001)$; the fall across the mid-range categories was

Table 2 Patient characteristics by NTSS-6-SA score category

\begin{tabular}{|c|c|c|c|c|c|c|}
\hline \multirow[t]{2}{*}{ Parameter } & \multicolumn{4}{|c|}{ NTSS-6-SA category } & \multirow[t]{2}{*}{ Ratio none to severe } & \multirow[t]{2}{*}{$p$} \\
\hline & None & Mild & Moderate & Severe & & \\
\hline Number of respondents & 335 & 199 & 196 & 202 & & \\
\hline Sex $(\%$ male $)$ & 56.2 & 57.5 & 61.4 & 58.1 & 1.0 & $0.486^{\mathrm{a}}$ \\
\hline \multicolumn{7}{|l|}{ Complication risk factors } \\
\hline Type 1 diabetes: age (years) & 41.8 & 57.4 & 56.2 & 61.4 & 1.5 & $<0.001^{\mathrm{b}}$ \\
\hline Type 2 diabetes: age (years) & 68.6 & 68.8 & 68.3 & 67.0 & 1.0 & $0.717^{\mathrm{b}}$ \\
\hline Type 1 diabetes: $\mathrm{HbA}_{1 \mathrm{c}}(\%)$ & 7.86 & 8.09 & 8.09 & 8.90 & 1.1 & $0.090^{\mathrm{b}}$ \\
\hline Type 2 diabetes: $\mathrm{HbA}_{1 \mathrm{c}}(\%)$ & 7.60 & 7.76 & 7.69 & 7.84 & 1.0 & $0.729^{\mathrm{b}}$ \\
\hline BMI & 28.02 & 30.03 & 29.66 & 30.91 & 1.1 & $<0.001^{\mathrm{c}}$ \\
\hline \multicolumn{7}{|l|}{ Neuropathy complications } \\
\hline Suffered from a leg or foot ulcer (\%) & 5.1 & 8.2 & 7.4 & 19.6 & 3.8 & $<0.001^{\mathrm{a}}$ \\
\hline Peripheral vascular disease (\%) & 0.6 & 5.5 & 4.5 & 8.4 & 14.0 & $<0.001^{\mathrm{a}}$ \\
\hline \multicolumn{7}{|l|}{ Health utility/quality of life } \\
\hline $\mathrm{EQ} \mathrm{D}_{\text {index }}$ & 0.81 & 0.63 & 0.52 & 0.25 & 3.2 & $<0.001^{\mathrm{b}}$ \\
\hline QoL-DN & 25.84 & 34.76 & 40.83 & 48.06 & 1.9 & $<0.001^{\mathrm{b}}$ \\
\hline \multicolumn{7}{|l|}{ SF36 } \\
\hline Role Physical & 52.23 & 20.13 & 13.04 & 4.29 & 12.2 & $<0.001^{\mathrm{b}}$ \\
\hline Role Mental & 70.86 & 50.19 & 34.01 & 17.89 & 4.0 & $<0.001^{\mathrm{b}}$ \\
\hline Physical Functioning & 74.39 & 48.07 & 45.04 & 23.81 & 3.1 & $<0.001^{\mathrm{b}}$ \\
\hline Bodily Pain & 78.68 & 53.32 & 44.83 & 28.23 & 2.8 & $<0.001^{\mathrm{b}}$ \\
\hline General Health Profile & 59.92 & 41.78 & 36.54 & 25.54 & 2.3 & $<0.001^{\mathrm{b}}$ \\
\hline Social Functioning & 83.01 & 66.55 & 54.04 & 38.68 & 2.1 & $<0.001^{\mathrm{b}}$ \\
\hline Vitality & 56.76 & 39.06 & 35.48 & 26.67 & 2.1 & $<0.001^{\mathrm{b}}$ \\
\hline Health Change & 52.64 & 45.85 & 41.28 & 31.97 & 1.6 & $<0.001^{\mathrm{b}}$ \\
\hline Mental Health & 78.59 & 71.45 & 64.58 & 54.01 & 1.5 & $<0.001^{\mathrm{b}}$ \\
\hline
\end{tabular}

Values adjusted for direction of the parameter. The mean value is shown unless otherwise stated.

${ }^{a}$ Linear by linear association

${ }^{\mathrm{b}}$ Kruskal-Wallis $H$-test

${ }^{\mathrm{c}}$ One-way ANOVA 
linear. Disease-specific quality of life showed a similarly linear association with increasing symptom severity (25.8 in GroupNone) through to 48.1 in Group-Severe; $p<0.001)$. This pattern was evident across the eight sub-domains of the SF36, not only for the total NTSS-6-SA score category but also for the individual NTSS-6-SA symptoms when grouped in category and DPN severity (Table 3 ).

A series of univariate and multivariate GLMs were constructed to determine the individual contribution of DPN symptom severity to health utility (measured by EQ5D) and quality of life (measured by QoL-DN).

Using Mann-Whitney $U$-tests to explore univariate associations, there were no significant differences in health utility measured by the EQ5D $\mathrm{D}_{\text {index }}$ between either sex $(p=0.761)$ or diabetes type $(p=0.629)$. There was a significant difference between patients with no diabetesrelated complications and those reporting one or more $(p<0.001)$. Thus stepwise linear regression modelling was conducted for these two groups separately with the covariates sex and type of diabetes (Table 4). Variables included in both models were age, BMI, NTSS-6-SA score, duration of diabetes and $\mathrm{HbA}_{1 \mathrm{c}}$. In both groups, the overall NTSS-6-SA score was strongly associated with reduction in health utility as measured by $\mathrm{EQ} 5 \mathrm{D}_{\text {index }}$. In those with no complications, with significant effects relating to age and BMI accounted for, each additional NTSS-6-SA point

Table 3 Health utility and quality of life change across NTSS-6-SA symptom score category

\begin{tabular}{|c|c|c|c|c|c|c|c|c|c|c|c|}
\hline \multirow[t]{2}{*}{ NTSS-6-SA } & \multicolumn{9}{|l|}{ SF36 } & \multirow[t]{2}{*}{ QoL-DN } & \multirow[t]{2}{*}{$\mathrm{EQ} 5 \mathrm{D}_{\text {index }}$} \\
\hline & Energy & Mental & $\begin{array}{l}\text { Role } \\
\text { Mental }\end{array}$ & $\begin{array}{l}\text { Role } \\
\text { Physical }\end{array}$ & Social & Physical & Pain & Change & GHP & & \\
\hline \multicolumn{12}{|l|}{ Aching } \\
\hline None & 52.26 & 77.16 & 66.03 & 44.22 & 78.46 & 68.20 & 72.53 & 50.00 & 55.16 & 28.08 & 0.76 \\
\hline Mild & 36.84 & 66.46 & 36.69 & 13.93 & 57.47 & 41.31 & 46.99 & 43.85 & 39.62 & 39.36 & 0.55 \\
\hline Moderate & 33.53 & 62.37 & 31.12 & 7.64 & 49.29 & 34.34 & 37.62 & 41.60 & 34.87 & 44.80 & 0.48 \\
\hline Severe & 23.85 & 51.57 & 17.62 & 2.52 & 37.28 & 21.38 & 24.18 & 28.83 & 22.29 & 45.47 & 0.15 \\
\hline$p$ & $<0.001$ & $<0.001$ & $<0.001$ & $<0.001$ & $<0.001$ & $<0.001$ & $<0.001$ & $<0.001$ & $<0.001$ & $<0.001$ & $<0.001$ \\
\hline \multicolumn{12}{|l|}{ Burning } \\
\hline None & 48.29 & 74.01 & 60.20 & 37.03 & 73.80 & 62.31 & 66.05 & 49.10 & 51.20 & 30.17 & 0.71 \\
\hline Mild & 34.70 & 64.74 & 30.78 & 10.38 & 51.44 & 37.08 & 42.75 & 39.32 & 35.76 & 42.37 & 0.48 \\
\hline Moderate & 30.13 & 53.88 & 20.81 & 7.89 & 43.89 & 30.00 & 33.28 & 37.36 & 30.80 & 44.38 & 0.34 \\
\hline Severe & 24.98 & 53.95 & 17.25 & 5.60 & 41.06 & 20.65 & 23.89 & 33.73 & 23.56 & 47.27 & 0.17 \\
\hline$p$ & $<0.001$ & $<0.001$ & $<0.001$ & $<0.001$ & $<0.001$ & $<0.001$ & $<0.001$ & $<0.001$ & $<0.001$ & $<0.001$ & $<0.001$ \\
\hline \multicolumn{12}{|l|}{ Prickling } \\
\hline None & 50.06 & 75.41 & 61.77 & 38.99 & 75.14 & 63.11 & 67.39 & 49.56 & 52.64 & 29.64 & 0.73 \\
\hline Mild & 33.75 & 64.25 & 30.73 & 9.18 & 53.16 & 36.84 & 42.98 & 39.88 & 35.80 & 41.50 & 0.49 \\
\hline Moderate & 29.67 & 55.59 & 26.58 & 8.25 & 42.65 & 31.64 & 34.33 & 37.95 & 27.86 & 45.52 & 0.31 \\
\hline Severe & 21.19 & 51.97 & 22.08 & 4.81 & 37.75 & 25.84 & 22.75 & 28.39 & 23.75 & 47.63 & 0.19 \\
\hline$p$ & $<0.001$ & $<0.001$ & $<0.001$ & $<0.001$ & $<0.001$ & $<0.001$ & $<0.001$ & $<0.001$ & $<0.001$ & $<0.001$ & $<0.001$ \\
\hline \multicolumn{12}{|l|}{ Numbness } \\
\hline None & 48.85 & 74.42 & 59.64 & 35.67 & 74.06 & 60.92 & 65.58 & 48.97 & 51.55 & 30.11 & 0.71 \\
\hline Mild & 32.81 & 61.57 & 24.02 & 9.08 & 49.14 & 35.39 & 39.84 & 38.42 & 33.29 & 43.75 & 0.44 \\
\hline Moderate & 29.64 & 60.40 & 26.64 & 7.99 & 42.71 & 32.43 & 36.14 & 36.69 & 31.04 & 44.24 & 0.34 \\
\hline Severe & 23.87 & 52.35 & 29.37 & 8.33 & 37.55 & 25.20 & 27.78 & 34.19 & 23.57 & 46.40 & 0.22 \\
\hline$p$ & $<0.001$ & $<0.001$ & $<0.001$ & $<0.001$ & $<0.001$ & $<0.001$ & $<0.001$ & $<0.001$ & $<0.001$ & $<0.001$ & $<0.001$ \\
\hline \multicolumn{12}{|l|}{ Sharp pain } \\
\hline None & 48.21 & 73.92 & 58.89 & 36.07 & 73.31 & 61.53 & 65.72 & 48.69 & 51.32 & 30.26 & 0.71 \\
\hline Mild & 31.96 & 62.29 & 29.76 & 9.17 & 49.67 & 35.83 & 39.39 & 37.65 & 33.73 & 43.98 & 0.44 \\
\hline Moderate & 28.59 & 54.67 & 23.28 & 7.47 & 42.67 & 29.61 & 30.61 & 37.76 & 26.12 & 44.63 & 0.34 \\
\hline Severe & 30.41 & 58.06 & 15.91 & 7.81 & 41.08 & 24.40 & 27.65 & 31.86 & 26.14 & 44.80 & 0.23 \\
\hline$p$ & $<0.001$ & $<0.001$ & $<0.001$ & $<0.001$ & $<0.001$ & $<0.001$ & $<0.001$ & $<0.001$ & $<0.001$ & $<0.001$ & $<0.001$ \\
\hline \multicolumn{12}{|l|}{ Sensitivity } \\
\hline None & 47.56 & 74.89 & 59.17 & 36.62 & 73.59 & 61.31 & 65.91 & 48.98 & 51.32 & 30.11 & 0.71 \\
\hline Mild & 35.48 & 61.33 & 28.25 & 9.13 & 50.35 & 38.64 & 40.24 & 38.61 & 34.68 & 43.21 & 0.46 \\
\hline Moderate & 30.46 & 56.63 & 30.14 & 9.62 & 43.22 & 30.08 & 36.19 & 35.42 & 31.32 & 46.22 & 0.38 \\
\hline Severe & 24.44 & 54.26 & 24.21 & 6.17 & 39.34 & 23.54 & 29.22 & 34.71 & 24.57 & 44.44 & 0.22 \\
\hline$p$ & $<0.001$ & $<0.001$ & $<0.001$ & $<0.001$ & $<0.001$ & $<0.001$ & $<0.001$ & $<0.001$ & $<0.001$ & $<0.001$ & $<0.001$ \\
\hline
\end{tabular}

Each NTSS-6-SA sub-domain recoded into zero and remaining thirtiles. All tests of significance relate to Kruskal-Wallis $H$-test 
Table 4 Stepwise linear regression model for health utility as measured by $\mathrm{EQ} \mathrm{D}_{\text {index }}$ and disease-specific quality of life as measured by QoL-DN

\begin{tabular}{|c|c|c|}
\hline Parameter & $\beta(95 \% \mathrm{CI})$ & $p$ \\
\hline \multicolumn{3}{|c|}{$\begin{array}{l}\mathrm{EQ5D}_{\text {index }} \text { (patients with no diabetes- } \\
\text { related complication): } n=453\end{array}$} \\
\hline Intercept & $\begin{array}{l}1.271(1.116 \text { to } \\
1.426)\end{array}$ & $<0.001$ \\
\hline NTSS-6-SA score & $\begin{array}{l}-0.043(-0.048 \\
\text { to }-0.037)\end{array}$ & $<0.001$ \\
\hline Age (years) & $\begin{array}{l}-0.003(-0.005 \\
\text { to }-0.001)\end{array}$ & $<0.001$ \\
\hline BMI & $\begin{array}{l}-0.010(-0.014 \\
\text { to }-0.006)\end{array}$ & $<0.001$ \\
\hline \multicolumn{3}{|c|}{$\begin{array}{l}\mathrm{EQ} \mathrm{D}_{\text {index }} \text { (patients with diabetes- } \\
\text { related complication/s): } n=177\end{array}$} \\
\hline Intercept & $\begin{array}{l}1.196(1.002 \text { to } \\
1.389)\end{array}$ & $<0.001$ \\
\hline NTSS-6-SA score & $\begin{array}{l}-0.044(-0.025 \\
\text { to }-0.036)\end{array}$ & $<0.001$ \\
\hline BMI & $\begin{array}{l}-0.016(-0.022 \\
\text { to }-0.009)\end{array}$ & $<0.001$ \\
\hline \multicolumn{3}{|l|}{ QoL-DN: $n=758$} \\
\hline Intercept & $\begin{array}{l}24.23(21.17 \text { to } \\
27.29)\end{array}$ & $<0.001$ \\
\hline NTSS-6-SA score & $\begin{array}{l}1.845(1.697 \text { to } \\
1.993)\end{array}$ & $<0.001$ \\
\hline Age (years) & $\begin{array}{l}0.080(0.032 \text { to } \\
0.128)\end{array}$ & $<0.001$ \\
\hline Sex (male) & $\begin{array}{l}-1.381(-2.748 \\
\text { to }-0.14)\end{array}$ & 0.048 \\
\hline
\end{tabular}

scored was associated with a reduction in the $\mathrm{EQ} 5 \mathrm{D}_{\text {index }}$ of 0.043 units $(95 \%$ CI: $0.038-0.049 ; p<0.001)$. For those with complications, only BMI emerged as another significant covariate, and with other confounding affects accounted for, the NTSS-6-SA point EQ5 $\mathrm{D}_{\text {index }}$ decrement was 0.044 units (95\% CI: $0.036-0.052 ; p<0.001)$.

In the model with the quality of life (measured by QoLDN) as dependent variable the overall NTSS-6-SA score was strongly associated with reduction in health-related quality of life. With effects relating to age and sex accounted for, each additional NTSS-6-SA point scored (ranging from 0 to 22) was associated with an increase (i.e. worse quality of life) in the QoL-DN score of 1.845 units (95\% CI: 1.697-1.993; $p<0.001$; Table 4). Independent variables entered in the initial model were: NTSS score, age, BMI, $\mathrm{HbA}_{1 \mathrm{c}}$, duration of diabetes, number of complications, sex, and sex $\times$ number of complications (interaction).

A similar pattern emerged for health-related quality of life as measured by the SF36. In a corrected model that allows for the independent contributions of BMI, $\mathrm{HbA}_{1 \mathrm{c}}$ and number of diabetic complications, each additional NTSS-6-SA point reduced the SF36 ${ }_{\mathrm{GHP}}$ by 2.55 units (95\% CI: $2.19-2.91 ; p<0.001)$.
When considering DPN-specific quality of life, a different model emerged, but one where the NTSS-6-SA score again showed a highly significant association (Table 4). After controlling for potential confounding by age and sex, each additional NTSS-6-SA point scored increased the QoL-DN score by 1.85 units (95\% CI: $1.697-$ $1.993 ; p<0.001)$

The final model was constructed with the intention of demonstrating the contribution of neuropathic symptoms to the distinct sub-domains of the SF36 (Table 5). In a multivariate GLM model built on the principles of corrected SF $36_{\mathrm{GHP}}$ score, the following associations emerged with severity category membership (categories None to Severe). SF $36_{\text {Vitality }}$ was reduced by aching and prickling by -5.12 $(p<0.001)$ and -7.08 units per ordinal category $(p<0.001)$, respectively. SF36 Mental Health sub-domain was reduced by aching, prickling, and sensitivity. The SF36 $6_{\text {Role }}$ Mental domain was decreased as aching, prickling and sharp pain increased. SF36 $6_{\text {Role Physical }}$ decreased markedly with more severe aching and prickling increased. SF36 $36_{\text {Social Functioning }}$ decreased with increasing aching, prickling, numbness and

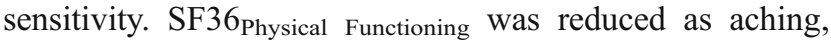
burning and numbness increased. SF36 $6_{\text {Bodily Pain }}$ correlated with aching and prickling whilst health change was most strongly associated with prickling and numbness.

Differences in drugs used to control symptoms

Rates of use of drugs known to modify some the symptoms of DPN shown above were classified in the survey. Over $50 \%$ of respondents in the highest NTSS-6-SA symptom category took some form of prescribed analgesia compared with just $12 \%$ of those with no neuropathic symptoms $(p<0.001)$. Antidepressant use also increased markedly by NTSS-6-SA symptom category from $5.9 \%$ among those with no symptoms to $19.8 \%$ in those with the severest DPN symptoms $(p<0.001)$. As a control exercise the use of thyroid hormones in these patients was chosen as a therapeutic category which was hypothesised to be unrelated to neuropathic symptoms. There was no meaningful association with increasing NTSS-6-SA symptom.

\section{Discussion}

This study gives detailed estimates of health utility and HRQoL for different disease states; in particular it highlights a difference in these health measures as a function of increasing severity of DPN as characterised by the NTSS-6SA, and does so in a way that accounts for confounding factors. The NTSS-6-SA score emerged as the most consistent and strongly correlated independent predictor of utility and HRQoL. This finding serves to underline the 


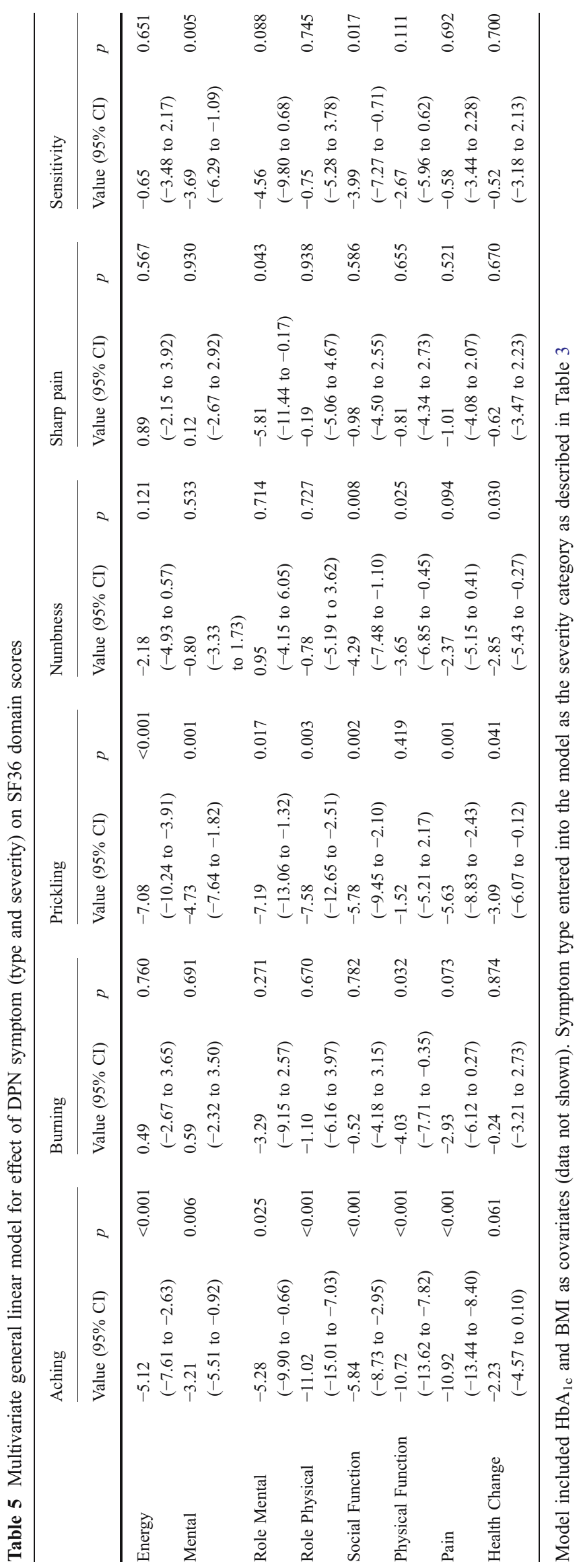


profound impact of DPN on patients affected by it. Although analgesia use correlated intuitively with NTSS6-SA score, a fourfold increase between those with no symptoms and severe symptoms raises questions about effectiveness of pain management in DPN. A more detailed examination of pain management regimen in DPN is certainly warranted to ascertain use of regular and breakthrough analgesia. The linear increase in NSAID use between no symptoms and moderate symptoms suggests that some patients' neuropathic pain may be associated with inappropriate pain management; a finding in common with other data [26].

The survey has a number of strengths. Diabetes in the geographical locations has been extremely well characterised in general by the same investigators, and for specific diabetes-related complications, including PVD [27]. Furthermore, the same methods have been used to characterise the impact on HRQoL of other diabetes-related factors such as obesity [28], hypoglycaemia [29] and diabetes in general [30]. Thus we can make direct comparisons of the health effects of different factors. A further strength was the availability of a clinical diagnosis of DPN by an experienced podiatrist (S.C.) in some patients.

However, several limitations should also be borne in mind when interpreting these data. The response rate to this survey was reasonable for this type of unsolicited survey [19]; nevertheless, there will always remain some doubt about the generalisability of some findings to the general diabetes population. HODaR data have been used to characterise HRQoL and health-related utility in an increasing number of diseases such as other complications of diabetes [30], obesity [28], hypoglycaemia specifically [29], renal failure [31] and urological problems [32]. Response rates are consistent across these studies, the methods are also well described and consistent with the HODaR protocol where no reminders are issued [19]. The inclusion of two global health measures and two DPN assessments could be argued to be unnecessary. The NTSS6-SA categorised frequency and severity of DPN symptoms whilst QoL-DN measures the effect of those symptoms on quality of life. Finally, the patients were identified from hospital sources; thus, it is likely that the general level of HRQoL and utility will be less than in the general population of people with diagnosed diabetes.

Nevertheless, regarding the capacity of the study design to answer the study question, the main necessity was to have survey responses from patients across the range of DPN severity, and this need was met; the general observations are therefore considered valid. No previous study has attempted to accurately classify the symptoms of DPN and relate this to HRQoL and health-related utility, making direct comparison with other studies difficult.

Our results showed that using the NTSS-6-SA, 76\% of respondents experienced some neuropathy-related symp- toms. The previous evidence shows that up to $60 \%$ will be affected by DPN and symptoms will be present in $20 \%$ [1]. This has implications for earlier management interventions and highlights the need to put patients into foot-protection programmes earlier.

The appropriateness of generic HRQoL instruments in DPN has been questioned [33], particularly their inability to assess the functional impact of DPN-specific problems such as balance disturbance, or symptoms of reduced feeling in the feet [34]. Some commentators have also pointed out that whilst general levels of functioning in specific domains are important, they are not direct appraisals of quality of life [35, 36]. Nevertheless, the SF36 is highly sensitive to changes in clinical status (a change of just five units has been shown clinically relevant) [37]. Additionally, the widespread application of generic measures in cost-effectiveness modelling of disease interventions in diabetes [38] justifies the inclusion of generic measures in this type of observational study by allowing comparison with other published findings.

This study may have a number of clinical and policy implications. It is believed that many cases of DPN go undiagnosed or are misdiagnosed $[26,39]$. The somewhat arbitrary labelling of the NTSS-6-SA thirtiles as Mild, Moderate and Severe deserves consideration as a formal classification system given the consistent linear associations with health utility, HRQoL and drug use. A tool such as the NTSS-6-SA could, moreover, be used to identify people with the symptoms of DPN, either in conjunction with or in preference to other clinical measures (such as the tuning fork [40]), since this may be a more reliable way of identifying patients with DPN symptoms, bearing in mind that these symptoms can also be caused by other problems such as musculoskeletal problems and are not necessarily neuropathic in origin. Nevertheless, someone scoring highly on the NTSS6-SA has severe health problems that should be addressed, irrespective of their origin.

Given the high prevalence of DPN as a complication of diabetes, surprisingly little is known about the distribution of symptom severity and its effect on HRQoL. This work goes some way to addressing this deficiency. People with diabetes should be prevented from progressing to advanced DPN. If allowed to do so, this will directly and markedly reduce their quality of life.

Acknowledgements We would like to thank the staff of the Health Improvement and Patient Outcomes (HIPO) project at Cardiff \& Vale NHS Trust for cooperation, and particularly the respondents to the survey for taking the time and trouble to complete the questionnaire. This study was funded by Eli Lilly and Company, Indianapolis. C. Ll. Morgan was funded by Diabetes UK (http://www.diabetes.org.uk/).

Duality of interest Other than funding (see Acknowledgements), there are no other conflicts of interest in regard to this study. The objectives of this study were neither company- nor product-specific. 


\section{References}

1. Dyck PJ, Kratz KM, Karnes JL et al (1993) The prevalence by staged severity of various types of diabetic neuropathy, retinopathy, and nephropathy in a population-based cohort: the Rochester Diabetic Neuropathy Study. Neurology 43:817-824

2. Young MJ, Boulton AJ, MacLeod AF, Williams DR, Sonksen PH (1993) A multicentre study of the prevalence of diabetic peripheral neuropathy in the United Kingdom hospital clinic population. Diabetologia 36:150-154

3. Tesfaye S, Stevens LK, Stephenson JM et al (1996) Prevalence of diabetic peripheral neuropathy and its relation to glycaemic control and potential risk factors: the EURODIAB IDDM Complications Study. Diabetologia 39:1377-1384

4. Quattrini C, Tesfaye S (2003) Understanding the impact of painful diabetic neuropathy. Diabetes Metab Res Rev 19(Suppl 1):S2-S8

5. Reiber GE (2001) Epidemiology of foot ulcers and amputations in the diabetic foot. In: Bowker JH, Pfeifer MA (eds) The diabetic foot, 6th edn. Mosby, St Louis, pp 13-32

6. Reiber GE, Lipsky BA, Gibbons GW (1998) The burden of diabetic foot ulcers. Am J Surg 176(Suppl 2A):5S-10S

7. Benbow SJ, Wallymahmed ME, MacFarlane IA (1998) Diabetic peripheral neuropathy and quality of life. Q J Med 91:733-737

8. Galer BS, Gianas A, Jensen MP (2000) Painful diabetic polyneuropathy: epidemiology, pain description, and quality of life. Diabetes Res Clin Pract 47:123-128

9. Lloyd CE, Orchard TJ (1999) Physical and psychological well-being in adults with type 1 diabetes. Diabetes Res Clin Pract 44:9-19

10. Lloyd A, Sawyer W, Hopkinson P (2001) Impact of long-term complications on quality of life in patients with type 2 diabetes not using insulin. Value Health 4:392-400

11. Padua L, Saponara C, Ghirlanda G et al (2001) Health-related quality of life in type 1 diabetic patients and influence of peripheral nerve involvement. Neurol Sci 22:239-245

12. Padua L, Saponara C, Ghirlanda G et al (2002) Lower limb nerve impairment in diabetic patients: multiperspective assessment. Eur J Neurol 9:69-73

13. Vickrey BG, Hays RD, Beckstrand M (2000) Development of a health-related quality of life measure for peripheral neuropathy. Neurorehabil Neural Repair 14:93-104

14. Bastyr EJ III, Price KL, Bril V, for the MBBQ Study Group (2005) Development and validity testing of the neuropathy total symptom score-6: Questionnaire for the Study of Sensory Symptoms of Diabetic Peripheral Neuropathy. Clin Ther 27:1278-1294

15. Currie CJ, Cawley S, Morgan CL et al (2005) Diabetic peripheral neuropathy: evaluation of the inter-association between the ranges of neuropathic symptoms. Value Health 8:A154 (Abstract)

16. Perrin NA, Nichols GA, Brown JB, Oglesby A, Bastyr EJ (2004) The reliability and validity of a self-administered version of the neuropathy total symptom score-6 (NTSS-6-SA). Diabetologia 47 (Suppl 1):87

17. Vinik AI, Bril V, Kempler P, for the MBBQ Study Group et al (2005) Treatment of symptomatic diabetic peripheral neuropathy with the protein kinase $\mathrm{C}$ b-inhibitor ruboxistaurin mesylate during a 1-year, randomized, placebo-controlled double-blind clinical trial. Clin Ther 27:1164-1180

18. Forst T, Nguyen M, Forst S, Disselhoff B, Pohlmann T, Pfutzner A (2004) Impact of low frequency transcutaneous electrical nerve stimulation on symptomatic diabetic neuropathy using the new Salutaris device. Diabetes Nutr Metab 17:163-168

19. Currie CJ, McEwan P, Peters JR, Patel TC, Dixon S (2005) The routine collation of health outcomes data from hospital treated subjects in the Health Outcomes Data Repository (HODaR): descriptive analysis from the first 20,000 subjects. Value Health 8:581-590
20. Vinik EJ, Hayes RP, Oglesby A et al (2005) The development and validation of the Norfolk QOL-DN, a new measure of patients' perception of the effects of diabetes and diabetic neuropathy. Diabetes Technol Ther 7:497-508

21. EuroQoL Group (1990) EuroQoL-a new facility for the measurement of health-related quality of life. Health Policy 16:199-208

22. Jenkinson C, Stewart-Brown S, Petersen S, Paice C (1999) Assessment of the SF36 version 2 in the United Kingdom. J Epidemiol Community Health 53:46-50

23. Dolan P (1997) Modeling valuations for EuroQol health states. Med Care 35:1095-1108

24. Hays RD, Sherbourne CD, Mazel RM (1993) The RAND 36-Item Health Survey 1.0. Health Econ 2:217-227

25. http://www.sf-36.org/images/maruishslide1.jpg [Accessed 7th September, 2005]

26. Rathmann W, Haastert B, Giani G (1999) Drug prescriptions and costs in diabetic polyneuropathy. Dtsch Med Wochenschr 124:681-686

27. Currie CJ, Morgan CL, Peters JR (1998) The epidemiology and cost of inpatient care for peripheral vascular disease, infection, neuropathy, and ulceration in diabetes. Diabetes Care 21:42-48

28. Lee AJ, Morgan CLl, Morrissey M, Wittrup-Jensen KU, Kennedy-Martin T, Currie CJ (2005) Evaluation of the association between the EQ5D $\mathrm{D}_{\text {index }}$ (health-related utility) and body mass index (obesity) in hospital-treated people with type 1 diabetes, type 2 diabetes and with no diagnosed diabetes. Diabet Med 22:1482-1486

29. Davis RE, Morrissey M, Peters JR, Wittrup-Jensen K, KennedyMartin T, Currie CJ (2005) Impact of hypoglycaemia on quality of life and productivity in type 1 and type 2 diabetes. Curr Med Res Opin 21:1477-1483

30. Morgan CLl, McEwan P, Morrissey M, Dixon S, Peters JR, Currie CJ (2006) Characterisation and comparison of healthrelated utility in people with and without diabetes in various states of single and multiple vascular complications. Diabet Med (in press)

31. Lee AJ, Morgan CLl, Conway P, Currie CJ (2005) Characterisation and comparison of health-related quality of life for patients with renal failure. Curr Med Res Opin 21:1777-1783

32. Currie CJ, McEwan M, Poole CD, Odeyemi IAO, Datta SN, Morgan CLl (2006) The impact of the overactive bladder on health-related utility and quality of life. BJU Int 97:12671272

33. Vileikyte L, Rubin RR, Leventhal H (2004) Psychological aspects of diabetic neuropathic foot complications: an overview. Diabetes Metab Res Rev 20(Suppl 1):S13-S18

34. Vileikyte L, Peyrot M, Bundy C et al (2003) The development and validation of a neuropathy- and foot ulcer-specific quality of life instrument. Diabetes Care 26:2549-2555

35. Bradley C (2001) Importance of differentiating health status from quality of life. Lancet $357: 7-8$

36. Leventhal H, Colman S (1997) Quality of life: a process view. Psychol Health 12:753-767

37. White CA, Pilkey RM, Lam M, Holland DC (2002) Pre-dialysis clinic attendance improves quality of life among hemodialysis patients. BMC Nephrol 3:3

38. Wu SY, Sainfort F, Tomar RH et al (1998) Development and application of a model to estimate the impact of type 1 diabetes on health-related quality of life. Diabetes Care 21:725-731

39. Berger A, Dukes EM, Oster G (2004) Clinical characteristics and economic costs of patients with painful neuropathic disorders. J Pain 5:143-149

40. Meijer JG, Smit AJ, Lefrandt JD, van der Hoeven JH, Hoogenberg $\mathrm{K}$, Links TP (2005) Back to basics in diagnosing diabetic polyneuropathy with the tuning fork! Diabetes Care 28:2201-2205 